\title{
Seasonality in the Consumer Response to Milk Advertising with Implications for Milk Promotion Policy
}

\author{
Henry Kinnucan; Olan D. Forker \\ American Journal of Agricultural Economics, Vol. 68, No. 3. (Aug., 1986), pp. 562-571.
}

Stable URL:

http://links.jstor.org/sici?sici=0002-9092\%28198608\%2968\%3A3\%3C562\%3ASITCRT\%3E2.0.CO\%3B2-I

American Journal of Agricultural Economics is currently published by American Agricultural Economics Association.

Your use of the JSTOR archive indicates your acceptance of JSTOR's Terms and Conditions of Use, available at http://www.jstor.org/about/terms.html. JSTOR's Terms and Conditions of Use provides, in part, that unless you have obtained prior permission, you may not download an entire issue of a journal or multiple copies of articles, and you may use content in the JSTOR archive only for your personal, non-commercial use.

Please contact the publisher regarding any further use of this work. Publisher contact information may be obtained at http://www.jstor.org/journals/aaea.html.

Each copy of any part of a JSTOR transmission must contain the same copyright notice that appears on the screen or printed page of such transmission.

The JSTOR Archive is a trusted digital repository providing for long-term preservation and access to leading academic journals and scholarly literature from around the world. The Archive is supported by libraries, scholarly societies, publishers, and foundations. It is an initiative of JSTOR, a not-for-profit organization with a mission to help the scholarly community take advantage of advances in technology. For more information regarding JSTOR, please contact support@jstor.org. 


\title{
Seasonality in the Consumer Response to Milk Advertising with Implications for Milk Promotion Policy
}

\author{
Henry Kinnucan and Olan D. Forker
}

Permitting seasonal variation in the goodwill effect in measuring the impact of fluid milk advertising on milk sales in New York City improved the statistical significance of the estimating equation. The allocation of generic advertising dollars according to optimization rules during the period 1979-81 would have resulted in a 9 percent increase in returns to dairymen supplying the New York City market. Harmonic variables are used to account for seasonality, a Pascal distribution is used to account for the decay structure, and goodwill elasticities are estimated to indicate the impact of generic advertising on sales.

Key words: advertising, generic advertising, goodwill, milk demand, milk promotion, seasonality.

The U.S. dairy industry over the last three decades has been plagued by a relatively stagnant demand for its products. Between 1955 and 1980 the per capita consumption of dairy products on a milk-equivalent basis declined by $24 \%$ (U.S. Department of Agriculture). Despite a $38 \%$ growth in population, the total consumption of dairy products increased by less than 5\% over this twenty-five-year period. Dairy farmers, in an effort to address this problem, have increased their investment in dairy product promotion and advertising. In New York state alone, nearly $\$ 8$ million was collected in 1983 under the State Dairy Product Promotion Order (Kling). Nationally, promotional expenditures by dairy farmers approached $\$ 200$ million annually in 1984 . $^{1}$

Previous research suggests that producerfunded promotion schemes can increase the

\footnotetext{
The authors are an assistant professor of agricultural economics, Auburn University, and a professor of agricultural economics, Cornell University, respectively.

Alabama Agricultural Experiment Station Journal No. 1-84617. Funds for this research were in part provided by the New York State Dairy Promotion Order.

The authors wish to acknowledge the helpful suggestions and criticisms of John Adrian, Greg Sullivan, Bill Tomek, and Lowell Wilson.

Review was coordinated by Peter Helmberger, associate editor.

${ }^{1}$ By the end of 1984 the $15 \not$ per hundredweight assessment on all milk produced in the $\mathbf{4 8}$ contiguous states yielded revenue of about $\$ 200$ million for generic promotion efforts, an increase of about $\$ 120$ million over 1983 levels. The authority for this assessment is the 1983 Dairy and Tobacco Adjustment Act (Novakovic).
}

demand for dairy products but that the profitability of the investment differs significantly by market (Thompson and Eiler 1975, Clement and Henderson, Kinnucan 1983). Intermarket differences in net producer returns from advertising fluid milk arise primarily because markets differ in their responsiveness to the advertising effort, but other factors are important. In particular, since milk sold for fluid use is more valuable than milk sold for manufacturing use, fluid milk advertising becomes more effective in raising the blend price of milk as Class I utilization rates and Class I-Class II price differentials increase (Thompson and Eiler 1977). Because Class I-Class II price differentials, Class I utilization rates, and the sales response to milk advertising vary over time as well as across markets (Kinnucan 1981), improved decisions regarding the allocation of promotion dollars can be made if information on the temporal variation in these factors is available.

In this paper, monthly data pertaining to New York City for the years 1971-80 were analyzed to determine if a seasonal response to milk advertising existed. Results were then used in simulations based on a modified version of the Thompson and Eiler (1977) model to obtain estimates of the optimal monthly expenditure for milk advertising. A regression 
equation was used to estimate the additional milk sales that would have occurred had the advertising budget been spent according to the computed "optimal" seasonal pattern. Finally, an estimate of the value to producers of following a prescribed seasonal advertising pattern was provided.

\section{The Model}

Empirical research on the effects of advertising indicates that advertising generally has a positive effect on sales which continues beyond the initial period of expenditure (Clarke) and is not proportional to expenditure, i.e., advertising is subject to diminishing marginal returns (Simon and Arndt). To take into account these hypotheses, most econometric studies of advertising use a distributed lag specification with variables expressed in logarithms; but this specification is complicated in the study of milk demand because the dependent variable is subject to seasonal variation which is not necessarily attributable to seasonal variation in the independent variables. Under these conditions the milk sales response to advertising may vary with the seasons. Econometrically, the existence of a seasonal relationship between milk sales and advertising expenditures could be tested using monthly dummy variables to date current and past advertising expenditures (see, e.g., Trivedi and Lee). This approach, however, is costly in terms of degrees of freedom, e.g., if the lag length is seven and there are twelve "seasons," then eighty-four degrees of freedom are required. An alternative approach, which is suggested by the Nerlove and Arrow treatment of advertising expenditures, is to specify in the demand equation a single variable, "goodwill." In this approach the goodwill variable summarizes the influence that current and past advertising expenditures have on sales, i.e.,

$$
A_{t}=\sum_{i=0}^{n} w_{i} a_{t-i},
$$

where $w_{i}$ is a weight factor which varies according to the decay structure of goodwill, and $n$ is the number of periods (possibly infinite) required for a current stock of goodwill to entirely depreciate. In addition to its intuitive appeal, the goodwill approach has the advantage of simplicity in terms of constructing tests for seasonality in the advertising response.
Incorporating the foregoing considerations, a demand equation of the following type was specified:

(2)

$$
\begin{gathered}
\ln q_{t}=\alpha_{0}+\alpha_{1} Z+\alpha_{2} \ln I_{t} \\
+\alpha_{3} \ln P M_{t}+\alpha_{4} \ln P C_{t}+\alpha_{5} \ln P C F_{t} \\
+\alpha_{6} \ln R A C E_{t}+\sum_{j=1}^{12} \eta_{j} D_{j, t} \ln A_{t}+\epsilon_{t},
\end{gathered}
$$

where $q_{t}$ is per capita daily fluid milk sales adjusted for the calendar composition of the month ${ }^{2} Z$ is a vector of eleven harmonic variables (Doran and Quilkey) to denote seasonality in the intercept term; $I_{t}$ is per capita beforetax personal income in 1967 dollars; $P M_{t}$, retail price of milk in paper quarter containers in 1967 dollars; $P C_{t}$, cola price index deflated by the consumer price index (CPI) $(1967=$ 100) for all items; $P C F_{t}$, coffee price index deflated by the CPI for all items; $R A C E_{t}$, percentage of the population which is nonwhite; $D_{i t}$, twelve zero-one dummy seasonality variables; and $A_{t}$, stock of goodwill (Nerlove and Waugh) measured as a weighted average of current and past advertising expenditures according to equation (1). Equation (2) is similar to the milk demand equation specified in Kinnucan $(1982$, p. 2) with some notable exceptions. First, milk sales follow a fairly regular seasonal pattern from year to year, dropping to a low point during the summer months. This pattern suggests that harmonic variables will adequately substitute for the eleven monthly intercept dummy variables used in the earlier specification. This substitution simplifies the model and, more important, reduces multicollinearity problems that arise when intercept and slope coefficients are specified to change simultaneously with the seasons. ${ }^{3}$ Second, equation (2) does not contain age and trend variables as did the earlier specification. Al-

\footnotetext{
${ }^{2}$ Milk sales vary according to the day of the week, e.g., milk sales are typically larger on Saturday than Sunday. The number of times a particular day occurs in any given month can vary yearly. For example, in 1973 January had five Mondays but only four Mondays in 1974. Calendar composition adjustment factors developed by the USDA can be used to remove this effect from the data (see Christ and Schlenker). Further details on their procedure and other aspects of the data are in a data appendix available upon request from the authors.

${ }^{3}$ The technique of harmonics involves initially specifying a separate harmonic for each season. Then, based on significance tests, "superfluous" harmonics are eliminated from the regression equation. Since each harmonic is orthogonal with respect to other variables in the equation, statistical efficiency is unaffected by the elimination of the superfluous harmonics. As discussed below, seven of the original eleven harmonics were found to be superfluous and hence were eliminated from equation (2).
} 
though potentially relevant, these variables are highly collinear with the race variable and with each other. Hence, their independent effects cannot be determined precisely by regression procedures and are omitted from the model. ${ }^{4}$ Finally, equation (2) differs fundamentally from previous specifications in that a single "goodwill" variable replaces the distributed lag specification of the advertising variable. Further, the "goodwill effect" is permitted to vary on a monthly basis via the use of dummy variables.

To simplify the estimation of an equation containing a goodwill variable, a Pascal distribution (Theil, p. 265) was used where

$$
w_{i}=\frac{(r+i-1) !}{(r-1) ! i !}(1-\lambda)^{r} \lambda^{i}
$$

and

$$
\sum_{i=0}^{n} w_{i}=1
$$

An advantage of the Pascal distribution is that it can assume a wide variety of shapes depending upon the choice of values for the two parameters $r$ and $\lambda$. For example, for $r=1$ the weights decline monotonically, but for $r=2$ they increase up to a certain maximum and then decline toward zero as $\lambda$ varies along the unit interval.

A formal test for seasonality in the milk sales response to goodwill (and by implication to advertising) can be constructed by forming the hypothesis

$$
\begin{aligned}
& H_{N}: \eta_{1}=\eta_{2} \ldots \ldots \ldots .=\eta_{12}=\eta^{*} \\
& H_{A}: H_{N} \text { not true }
\end{aligned}
$$

where $\eta_{j}$ represents the twelve monthly goodwill elasticities specified in equation (2). Under the null hypothesis that the goodwill elasticity is invariant with respect to seasons, equation (2) is reduced to

(5) $\ln q_{t}=\alpha^{\prime}{ }_{0}+\alpha^{\prime}{ }_{1} Z+\alpha^{\prime}{ }_{2} \ln I_{t}$

$$
\begin{aligned}
+\alpha^{\prime} & \ln P M_{t}+\alpha^{\prime}{ }_{4} \ln P C_{t}+\alpha^{\prime}{ }_{5} \\
+\ln P C F_{t}+\alpha^{\prime}{ }_{6} & \ln R A C E_{t} \\
& +\eta^{*} \ln A_{t}+\epsilon^{\prime}{ }_{t} .
\end{aligned}
$$

An $F$-test, which compares the residual sums of squares (RSS) from equation (5) with the

\footnotetext{
${ }^{4}$ The nature of the bias introduced into the estimated parameters of the milk demand equation when age or race factors are ignored is discussed in Kinnucan (1982). That analysis showed advertising effects having a downward bias if demographic factors are ignored. However, the inclusion of age or race in the model was found to reduce substantially the magnitude of this bias.
}

RSS of equation (2) provides an objective basis for discriminating between the null and alternative hypotheses.

\section{The Data}

Data pertaining to the New York City metropolitan area were used to estimate the equations. These data were chosen because nonbrand advertising and promotion of milk in this market has been heavy $(\$ 12.2$ million in media advertising between 1971-80), and monthly sales and advertising data over an extended period of time (January 1971-June 1980) were readily available.

While milk sales exhibited a regular seasonal pattern over the sample period, advertising expenditures varied widely from month to month and showed no seasonal pattern. The relatively random variation in the advertising data was fortuitous because it permitted regression estimates of the advertising effect to be estimated efficiently. In addition, the potential problem of a spurious correlation between sales and advertising that arise when advertising expenditures are budgeted to vary with the volume of sales (Ashley, Granger, and Schmalensee) was minimized. Finally, the fact that the highest and lowest levels of advertising did not consistently occur in the same months each year means that seasonality in the advertising effect would not be caused by the level of advertising.

\section{Regression Results}

Equations (2) and (5) were estimated under the assumption that an expenditure contributes to goodwill for only six months; i.e., $n$ in equation (1) was restricted to equal six. This assumption seems reasonable; Clarke, in a survey of the econometric literature dealing with sales-advertising studies concluded that " 90 percent of the cumulative effect of advertising on sales of mature, frequently purchased, lowpriced products occurs within 3 to 9 months of the advertisement" (p. 355). In addition, specific studies relating to milk demand indicate a sales-advertising lag ranging from two to six months (Thompson, Eiler, and Forker; Kinnucan 1982). Moreover, the length of the goodwill decay period in equation (2) is assumed invariant across the seasons.

To further simplify the estimation, $r=2$ is 
Table 1. Regression Results for Two Alternative Specifications of the Milk Demand Equation, New York City Metropolitan Area, July 1971-June 1980 Data

\begin{tabular}{|c|c|c|c|c|}
\hline \multirow{2}{*}{$\begin{array}{l}\text { Independent } \\
\text { Variable }\end{array}$} & \multicolumn{2}{|c|}{ Model A } & \multicolumn{2}{|c|}{ Model B } \\
\hline & Coefficient & $t$-ratio & Coefficient & $t$-ratio \\
\hline Intercept & -6.574 & -4.80 & -7.023 & -5.78 \\
\hline sine $_{1}$ & 0.024 & 6.03 & 0.089 & 1.83 \\
\hline $\cos _{1}$ & 0.026 & 6.87 & -0.011 & -0.23 \\
\hline $\operatorname{sine}_{2}$ & -0.023 & -6.38 & -0.058 & -1.26 \\
\hline $\cos _{4}$ & 0.018 & 4.90 & 0.037 & 0.83 \\
\hline Income & 1.124 & 6.13 & 1.191 & 7.32 \\
\hline Milk price & -0.040 & -0.52 & -0.037 & -0.54 \\
\hline Cola price & 0.151 & 2.98 & 0.154 & 3.41 \\
\hline Coffee price & 0.022 & 1.44 & 0.026 & 1.88 \\
\hline Race & -0.395 & -2.84 & -0.431 & -3.46 \\
\hline $\mathrm{A}^{\mathbf{a}}$ & 0.056 & 6.60 & & \\
\hline A* Jan & & & 0.052 & 3.32 \\
\hline A* Feb. & & & 0.058 & 3.70 \\
\hline A* Mar. & & & 0.076 & 5.31 \\
\hline A* Apr. & & & 0.078 & 5.80 \\
\hline A* May & & & 0.074 & 5.77 \\
\hline A* June & & & 0.068 & 5.43 \\
\hline A* July & & & 0.056 & 4.33 \\
\hline A* Aug. & & & 0.049 & 3.72 \\
\hline A* Sept. & & & 0.050 & 3.87 \\
\hline A* Oct. & & & 0.048 & 3.66 \\
\hline A* Nov. & & & 0.056 & 4.24 \\
\hline A* Dec. & & & 0.062 & 4.32 \\
\hline$R^{2}$ & & & & \\
\hline $\bar{R}^{2}$ & & & & \\
\hline$F$ & & & & \\
\hline DW & & & & \\
\hline RSS & & & & \\
\hline
\end{tabular}

a The advertising variable $A$ in each model is measured as a weighted average of current and past advertising expenditures. Specifically, $A=w_{1} a_{t-1}+w_{2} a_{t-2}+\ldots+w_{t} a_{t-6}$ where the $w_{i}$ are Pascal weights. See text for details on the procedure used to determine the weights.

assumed. The justification for this assumption rests on the empirical studies by Bultez and Naert, who found estimated goodwill elasticities based on the Pascal distribution stabilizing for $r$ values greater than one.

The appropriate value for $\lambda$, the Pascal distribution parameter, was determined by applying ordinary least squares (OLS) iteratively to equation (5) allowing $\lambda$ to assume a range of values within the unit interval. The value of $\lambda$ (to two decimal places) yielding the highest explanatory power for the model in terms of $R^{2}$ was deemed "best." This approach is equivalent to a maximum likelihood procedure for estimating the parameters. Friedman and Meiselman (quoted in Rao and Miller, p. 18) provide the rationale for the approach: "the argument for this procedure is that the precise empirical definition of variables should be selected so as to put theory in question in its best light."

The regression results indicate that a global maximum in $R^{2}$ for the constant-seasonality model was achieved when $\lambda=0.76$ (table 1 , model A). The regression equation "explains" $73 \%$ of the observed variation in milk sales and represents a statistically significant relationship as indicated by the $F$-value ( $F=25.6$ compared with a $1 \%$ critical $F$-value of 1.88$).^{5}$ The Durbin-Watson statistic (D.W. = 1.55) suggests the absence of first-order serial correlation. A regression test for twelfth-order serial correlation was also negative. ${ }^{6}$

Following Doran and Quilkey, the model was initially estimated with eleven harmonic variables. Based on significance tests, all but four harmonics were deemed superfluous. The

\footnotetext{
5 The reader is cautioned that $F$-values and $t$-ratios may overstate the level of significance when the same data are used both to select a model by prior testing and to estimate parameters in the final specification (Wallace). The same caution applies to tests of significance discussed below.

${ }^{6}$ When monthly data are used to estimate a model where seasonal variation exists in the dependent variable, twelfth-order autocorrelation is more likely to be a problem than first-order autocorrelation, particularly if the regressors inadequately account for seasonality (see Wallis).
} 
retained harmonics were all significant at the one percent level. The two "fundamental harmonics," sine $e_{1}$ and $\cos _{1}$, together accounted for $61 \%$ of the total seasonality explained by the original eleven. The sine 2 and $\cos _{4}$ harmonics contributed an additional $24 \%$ to the explained seasonality, so that these four harmonic variables together represent $85 \%$ of the total seasonality explained by the original set of eleven harmonics. ${ }^{7}$

The income elasticity was estimated to be 1.12 and is significant. The magnitude of this elasticity seems implausibly large since most studies have found the demand for milk to be income-inelastic. For example, Boehm put the income elasticity for milk in the New York City market at 0.088-0.168 (p. 41). One explanation may be that the omission of age and trend variables from the model resulted in an upward bias. When these two variables were included in the model, the estimated income elasticity became a more plausible 0.416 (Kinnucan 1982 , p. 6).

The estimated price elasticity for milk is -0.040 . This estimate, while imprecise as indicated by its large standard error, is consistent with findings of other studies which show the demand for milk to be price inelastic in the short run. For example, the Boehm study put the own-price elasticity for milk in New York at -0.136 to -.328 . The imprecision of the estimated price effect in the current study may be because the real price of milk was nearly constant over the period studied.

The estimated cross elasticities pertaining to soft drinks and coffee are positive but small, indicating that consumers regarded these beverages as weak substitutes for milk. The $t$-ratios indicate that the estimated cola and coffee cross-price elasticities are significant at the one percent and $15 \%$ levels, respectively.

The goodwill elasticity estimate of 0.056 is significant at the one percent level. This estimate is consistent with the findings of Lambin (cited in Bultez and Naert, p. 463, fn. 23) that most estimated sales-goodwill elasticities are less than 0.10 . The decay structure for goodwill implied by the Pascal distribution when $\lambda$ $=0.76$ is hump-shaped. Specifically, the weights, normalized to sum to one, are $w_{0}=$

\footnotetext{
${ }^{7}$ The formula used to compute this percentage was $V_{k}=\zeta_{k}{ }^{2} /$ $\sum_{i=1}^{11} \zeta_{i}^{2}$, where $V_{k}$ is a measure of the contribution of $k$ th harmonic term to the total seasonal variation explained by the model, and $\zeta_{i}$ is the OLS estimate of the effect of the $i$ th harmonic term (Doran and Quilkey, p. 648)
}

$0.101, w_{1}=0.153, w_{2}=0.174, w_{3}=0.175, w_{4}$ $=0.167, w_{5}=0.153, w_{6}=0.078$. OLS estimates of equation (2) indicate that a value of $\lambda$ $=0.76$ also maximizes $R^{2}$ in the seasonality varying-slope model (table 2 ). This model "explains" $81 \%$ of the variation in milk sales, compared with $73 \%$ for the constant-slope model. An $F$-test indicated that the hypothesis of no seasonal variation in the goodwill elasticity can be rejected at the one percent level of statistical significance $[F=3.63$ compared with $\left.F_{c}(0.01 ; 11,86)=2.47\right]$. Whether the model was specified in constant- or varyingslope form did not appreciably affect the estimated parameters of the economic and race variables ( $t$-ratios for these variables are somewhat larger in the varying-slope model, however).

In addition to the statistically significant improvements in explanatory power achieved by the model specification which permitted seasonal variation in the goodwill effect, the OLS estimates of the individual monthly goodwill elasticities themselves are precisely determined as judged by their large $t$-ratios (all in excess of 3.22). These estimates trace a smooth seasonal pattern, i.e., peaking in the spring and troughing in the summer months. Because milk sales have a similar pattern, this finding suggests that the cumulative effect of milk advertising on sales was greatest (least) in months when consumers have the strongest (weakest) preference for milk. In particular, the estimated goodwill elasticities indicate that the cumulative effects of milk advertising during the months of March, April, and May were nearly twice as large as during the months of August, September, and October. Furthermore, sensitivity analysis revealed that the estimated seasonal pattern in the goodwill elasticities was preserved across a wide range of assumed shapes for the decay structure for goodwill: choosing values of $\lambda$ less than 0.76 only accentuated this seasonal pattern, while values of $\lambda$ near unity reduced the seasonal variation but did not change the seasonal pattern.

Disaggregating the goodwill elasticities to reveal the underlying decay structure provides some insight into the effects that seasonally varying preferences for milk may have on the effectiveness of advertising milk in different seasons. For example, advertising milk in March, the month when per capita milk consumption was typically at its highest level in New York City, has a greater initial, peak, and 
Table 2. Milk Advertising: Actual Vs. Optimal Monthly Allocation of the Annual Budget, New York City Metropolitan Area, 1977-79

\begin{tabular}{|c|c|c|c|c|c|c|}
\hline \multirow[b]{2}{*}{ Month } & \multicolumn{2}{|c|}{1977} & \multicolumn{2}{|c|}{1978} & \multicolumn{2}{|c|}{1979} \\
\hline & Actual & Optimal & Actual & Optimal & Actual & Optimal \\
\hline January & 0.0 & 10.0 & 1.9 & 10.1 & 2.2 & 9.3 \\
\hline February & 5.0 & 9.2 & 7.8 & 9.1 & 7.6 & 9.2 \\
\hline March & 10.7 & 9.2 & 10.7 & 9.6 & 8.1 & 9.7 \\
\hline April & 1.0 & 7.4 & 10.4 & 9.0 & 15.5 & 8.8 \\
\hline May & 9.1 & 7.9 & 7.8 & 9.2 & 10.1 & 8.8 \\
\hline June & 14.8 & 8.5 & 10.0 & 9.2 & 7.6 & 8.0 \\
\hline July & 16.6 & 8.0 & 10.3 & 8.4 & 9.7 & 7.3 \\
\hline August & 6.1 & 7.7 & 8.1 & 6.7 & 9.1 & 6.5 \\
\hline September & 4.6 & 7.6 & 4.5 & 6.2 & 12.1 & 6.2 \\
\hline October & 15.6 & 8.3 & 12.8 & 7.2 & 6.4 & 8.0 \\
\hline November & 11.8 & 8.0 & 7.0 & 7.1 & 8.9 & 9.1 \\
\hline December & 4.8 & 8.2 & 8.8 & 8.2 & 2.8 & 9.1 \\
\hline Annual & 100 & 100 & 100 & 100 & 100 & 100 \\
\hline
\end{tabular}

total effect than does advertising milk in July, a month of relatively low milk consumption (fig. 1). Further, March advertising achieves its maximum impact two months later, whereas July advertising does not achieve its maximum impact until five months later. These comparisons highlight the importance that seasonally varying preferences in demand may have on the structure of the dynamic response of sales to advertising.

\section{Simulation Results}

The statistical analysis presented above suggests significant seasonal differences in the

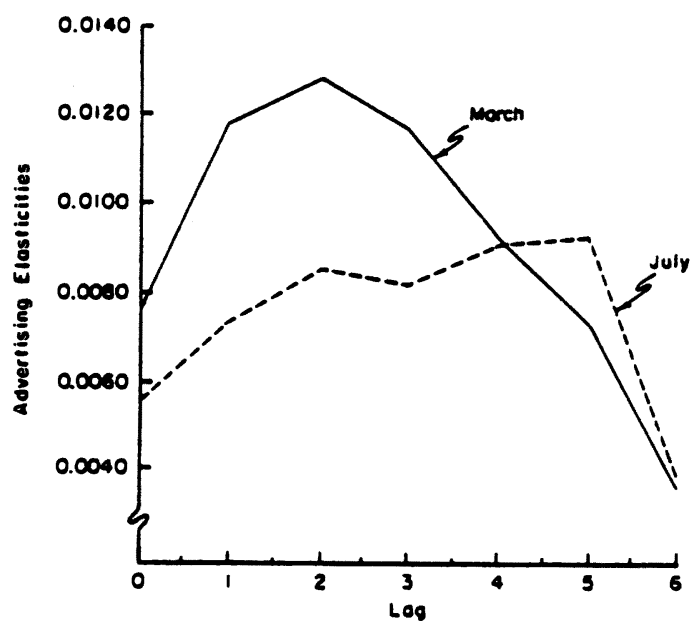

Figure 1. Advertising lag structures for milk advertisements placed in March vs. July, New York City metropolitan area ability of milk advertising to influence sales. Temporal changes in other key factors which influence the economic effectiveness of milk advertising discussed above suggest that improved decisions could be made if seasonal variations in these parameters were taken into account. To explore this hypothesis, the economic model developed by Thompson and Eiler (1977) was extended to permit monthly variation in all the key parameters. This model, as originally designed, determines the farm-level profitability of a given advertising expenditure on fluid milk for assumed values of $(a)$ the Class I-Class II price differential, $(b)$ the Class I utilization rate, $(c)$ the price elasticity of supply, and $(d)$ the long-run advertising elasticity. Application of the model requires values for $\boldsymbol{P}_{B}$, the blend price of milk, $\boldsymbol{P}_{\mathrm{II}}$ the price of Class II milk, $P_{D}$ the price difference between Class I and Class II milk, $k$ the Class I utilization rate, $a$ the intercept of the milk supply equation, $b$ the slope of the milk supply equation, $c$ the intercept of the Class I demand equation, and $\beta$ the estimated long-run advertising elasticity.

Milk price data were obtained from the Market Administrators' Bulletin for the New York-New Jersey Marketing Area. The supply equation parameters were computed from the formulas $a=Q(1-\gamma)$ and $b=Q / P_{B} \gamma$, where $Q$ is total quantity of milk supplied to the market, $\gamma$ is price elasticity of supply, and $P_{B}$ is uniform blend price of milk. A value for $Q$ was computed from the equation $Q=Q_{\mathrm{I}} / k$, where $Q_{\mathrm{I}}$ is the estimated quantity of Class I milk supplied to the market [based on the regression equation (5)] and $k$ is the proportion of 
milk production sold as Class $\mathrm{I}$ in the Federal Order 2 marketing area. A value of 0.8 was used for $\gamma^{8}$ Annual average values, rather than monthly values, for $P_{B}$ and $P_{\mathrm{II}}$ were used since model results were not sensitive to these parameters.

Values used for the demand parameters $c$ and $\beta$ were based on the regression estimates of the milk demand equation (table 1 , model B). The intercept $c$ was composed of all variables except goodwill evaluated at their mean values. This procedure provided a value of $c$ $=2.54462$. Values for $\beta_{j}$ were derived from the estimated goodwill elasticities presented in table $1 .^{9}$

Results indicate that optimal monthly expenditures exceed actual monthly expenditures over the entire thirty-six-month period (1977-79) for which simulations were run. ${ }^{10}$ Furthermore, the optimal monthly allocation was similar in each of the three years, generally being highest in the first quarter and lowest in the third quarter (table 2). By comparison, the actual monthly expenditure pattern was highly irregular from year to year. For example, during the years 1977-79 actual advertising expenditures in January never exceeded $2.2 \%$ of the annual budget, whereas the model results suggested an average budget allocation of $9.8 \%$ for January.

\footnotetext{
${ }^{8}$ Sensitivity analysis revealed that the model results were not greatly affected by changes in the price elasticity of supply (Thompson and Eiler 1977). The $\gamma=0.80$ was the "best estimate" for long-run supply response used by Thompson and Eiler.

${ }^{9}$ Because the long-run advertising elasticities called for in the economic model differ conceptually from goodwill elasticities, an adjustment had to be made. Values for $\beta_{j}$ were derived from the estimated goodwill elasticities in two-step procedure. First, the goodwill elasticities were disaggregated using the formula $\beta_{i j}=$ $w_{i} \eta_{j}$, where $w_{i}(i=1,2, \ldots, 6)$ are the Pascal lag weights (assumed invariant across seasons) and $\eta_{j}$ is the estimated goodwill elasticity corresponding to the $j$ th month ( $j=1$ for January, $j$ $=2$ for February, etc.). This step provides an estimate of the effect of advertising expenditures placed in the $j-i$ month on sales in the $j$ th month. The $B_{i j}$ 's were then recombined to provide estimates of the implied monthly long-run advertising elasticities; $\boldsymbol{B}_{j}$ values were $B_{1}=.068, B_{2}=.068, B_{3}=.065, B_{4}=.060, B_{5}=$ $.056, B_{6}=.054, B_{7}=.053, B_{8}=.053, B_{9}=.056, B_{10}=.061, B_{11}$ $=.065$ and $B_{12}=.067$. Note that in most instances the derived advertising elasticities do not differ significantly from the corresponding goodwill elasticities listed in table 1 . Thus, the practical importance of distinguishing between long-run advertising elasticities from goodwill elasticities may be small in terms of fund allocation.

10 The "optimal" expenditure is that level of advertising which maximizes producers' surplus less the cost of advertising at some specified rate of return on alternative forms of investment. As Nerlove and Waugh point out (pp. 825, 833) the "optimal"' level so computed actually represents only an upper bound to the optimal level of advertising. The most recent three-year period is used for model simulation because it was felt that results for earlier years would be of little more than historical significance.
}

\section{Economic Benefits of a Seasonal Allocation of} Advertising Expenditures

The above results indicate that producer returns from milk advertising would be maximized when the expenditures followed a regular seasonal pattern. The wide disparity between the actual and the optimal expenditure pattern found in this study suggests that the economic effectiveness of milk advertising in New York City could have been enhanced had the actual expenditure pattern more nearly approximated the optimal pattern. To test this hypothesis, the econometric model estimated earlier (table 1, model B) was used to estimate monthly milk sales assuming that the annual advertising budget of each calendar year had been allocated across the quarters according to a 30-25-20-25 rule. This rule approximates the optimal seasonal allocation by spreading $30 \%$ of the annual advertising budget evenly among the months in the first quarter, $25 \%$ among the months in the second quarter, $20 \%$ among the third-quarter months, and $25 \%$ among the fourth-quarter months. The same econometric model was then used to estimate monthly sales given the actual pattern of advertising expenditures. The difference in these estimates is the additional milk sales attributable to the seasonal allocation of the advertising expenditures. Following Thompson and Eiler (1977), the farm value of this sales difference was then computed as the per capita monthly milk sales gain (loss) multiplied by the Class I-Class II price differential of the corresponding month times the New York City SMSA population.

Results indicate that milk sales in every year but one (1973) would have been higher had the 30-25-20-25 rule been followed (table 3). ${ }^{11}$ Per capita milk sales for the period Janu-

\footnotetext{
${ }^{11}$ Note that the reallocation can result in greater producer returns even if no increase in annual milk sales occurs, e.g., the reallocation may simply result in less milk being sold in months when milk is worth less and more sold in months when fluid milk is more highly valued with no net change in annual sales. Further, the 30-25-20-25 rule used to allocate the annual advertising budget, while fairly accurate for the period 1977-79 as judged from the simulation results, probably deviates to a greater extent from the optimal rule in some of the earlier years because of occasional large irregular monthly swings in the Class I-Class II price differential. Thus, the generally consistent positive annual results obtained from application of this crude rule over the earlier years suggests that even an imprecise seasonal allocation of advertising expenditures, along the lines suggested by the economic model, is an improvement (in terms of increasing milk sales) upon an allocation which does not take into account monthly changes in the key parameters which determine the economic effectiveness of milk advertising.
} 
Table 3. Estimated Milk Sales under the Seasonal and the Actual Allocation of the Advertising Budget, New York City Metropolitan Area, January 1972-June 1980

\begin{tabular}{|c|c|c|c|c|}
\hline \multirow[b]{2}{*}{ Year } & \multicolumn{2}{|c|}{ Estimated Milk Sales Given the: } & \multirow{2}{*}{$\begin{array}{l}\text { Additional Milk } \\
\text { Sales Attributable } \\
\text { to the } \\
\text { Seasonal Allocation }\end{array}$} & \multirow{2}{*}{$\begin{array}{c}\text { Farm Value } \\
\text { of the } \\
\text { Milk Sales } \\
\text { Difference } \\
\end{array}$} \\
\hline & $\begin{array}{l}\text { Seasonal Allocation } \\
\text { of the } \\
\text { Advertising Budget }\end{array}$ & $\begin{array}{l}\text { Actual Allocation } \\
\text { of the } \\
\text { Advertising Budget }\end{array}$ & & \\
\hline & & --(ounces per cap & -1..-- & (undeflated \$) \\
\hline 1972 & 3,255 & 3,168 & 87 & $1,567,796$ \\
\hline 1973 & 3,281 & 3,292 & -11 & $-174,850$ \\
\hline 1974 & 3,268 & 3,246 & 22 & 552,128 \\
\hline 1975 & 3,300 & 3,297 & 3 & 15,741 \\
\hline 1976 & 3,243 & 3,215 & 28 & 463,762 \\
\hline 1977 & 3,328 & 3,270 & 58 & $1,090,715$ \\
\hline 1978 & 3,410 & 3,395 & 15 & 263,648 \\
\hline 1979 & 3,336 & 3,327 & 9 & 134,254 \\
\hline $1980^{a}$ & 1,663 & 1,655 & 7 & 133,363 \\
\hline $1972-80$ & 28,084 & 27,866 & 218 & $4,046,557$ \\
\hline
\end{tabular}

a First six months only.

ary 1972-June 1980 were estimated to be 218 ounces $(0.78 \%)$ higher under the seasonal allocation. The farm value of the additional sales, in undeflated dollars, is $\$ 4,046,557$. Compared with estimates of the farm value of the advertising-induced milk sales increase computed earlier (Kinnucan 1982), these results suggest that producer returns would have been $9 \%$ higher had the advertising budget followed a prescribed seasonal allocation over the sample period.

\section{Limitations}

The procedure used to estimate the seasonality in the response to advertising (the major innovation of this study) imposes a number of implicit restrictions which may influence the estimated pattern. For example, the assumption that the lag weights and lag lengths are invariant with respect to seasons may be inappropriate. The sensitivity of the estimated goodwill elasticities to this assumption cannot be determined a priori. A longer time series of data is required before these restrictions can be relaxed. In the meantime, the finding by Bultez and Naert (p. 460) that "different lag structures will not lead to very different implications for decision making" plus the plausibility and statistical quality of the results may mean that the practical implications of the restrictions are innocuous.

This study fails to take into account a num- ber of additional factors that affect seasonal advertising allocation decisions. Advertising behavior by competitive beverage manufacturers was ignored. The tendency for soft drink advertisements to peak during the summer months may explain the apparent reduced effectiveness of milk advertising during these months. If this nexus is valid, then a shift in the seasonal pattern of soft drink advertising (or advertisements for other beverages) may result in a shift in the seasonal pattern of consumer response to milk advertising. Similarly, the potential influence of seasonal or shortterm changes in the price of competitive beverages on the advertising elasticity is ignored. Presumably, milk advertising would be more effective in months when soft drink, coffee, or beer prices were higher, ceteris paribus. Given the relatively large short-term changes that have occurred in recent years in coffee and soft drink prices, it may be worthwhile to take a closer look at the nature of the relationship between advertising elasticities and cross-price elasticities as they relate to milk demand.

Finally, this study does not explicitly account for the cost savings that advertising agencies may achieve by having complete discretion over the monthly distribution of the annual advertising budget. The economic effectiveness of the seasonal allocation rule would be reduced to the extent that a predetermined monthly allocation of the annual advertising budget would result in fewer advertisements. The estimates presented in table 3 
provide a basis for deciding whether potential benefits from this source offset the costs.

\section{Concluding Remarks}

Milk-advertising expenditures evenly distributed over the year, with only small fluctuation occurring in concert with demand shifts, gain corroborative support at both the theoretical and empirical level. In a theoretical analysis of advertising policy under dynamic conditions, Nerlove and Arrow concluded that (under plausible assumptions) firms should try to keep a constant ratio of sales to advertising. The optimal milk-advertising expenditure pattern computed in this study is consistent with this finding. Further corroborative evidence is provided in a "pulsing" study conducted by Zielske who found that (p. 241) "the average weekly number of housewives who could remember the advertising, in the 52-week period covered by the experiment, was higher for thirteen exposures spread out over the year (29 percent) than for the same number of exposures concentrated in the first thirteen weeks of the year ( 21 percent)."

Results suggest that appropriate timing of milk-advertising expenditures can increase the effectiveness of the investment. Monthly changes in the farm value of Class I milk, the Class I utilization rate, and the ability of milk advertising to influence sales affect the profitability of the advertising investment. Managers of milk promotion funds will want to take a close look at likely changes in these factors so as to allocate annual advertising budgets throughout the year in a manner which provides the maximum possible return from the advertising investment.

\section{[Received May 1984; final revision received November 1985.]}

\section{References}

Ashley, R., C. W. J. Granger, and R. Schmalensee. "Advertising and Aggregate Consumption: An Analysis of Causality." Econometrica 48(1980):1149-67.

Boehm, W. T. "The Household Demand for Fluid Milk in the United States with Regional Consumption Projections Through 1990." Virginia Polytechnic Institute and State University Res. Div. Bull. No. 120, Dec. 1976.

Bultez, A. V., and P. A. Naert. "Does Lag Structure Really Matter in Optimizing Advertising Expenditures." Manage. Sci. 25(1979):454-65.
Christ, P., and A. Schlenker. "Adjusting in Area Sales Data for Calendar Composition." Federal Order Marketing Statistics, No. 158. Washington DC: U.S. Department of Agriculture, Agr. Mktg. Serv., April 1973.

Clarke, D. C. "Econometric Measurement of the Duration of Advertising Effect on Sales." J. Mktg. Res. 13(1976):345-57.

Clement, Wendell E., and Peter L. Henderson. "Consumer Response to Various Levels of Advertising for Fluid Milk." Washington DC: U.S. Department of Agriculture, Econ. Res. Serv. Mktg. Res. Rep. No. 805, Oct. 1967.

Doran, H. E., and J. J. Quilkey. "Harmonic Analysis of Seasonal Data: Some Important Properties." Amer. J. Agr. Econ. 54(1972):646-51.

Friedman, M., and D. Meiselman. "The Relative Stability of Monetary Velocity and the Investment Multiplier in the United States, 1897-1958." Stabilization Policies. New York: Commission on Money and Credit, 1963.

Kinnucan, H. W. Demographic Versus Media Advertising Effects on Milk Demand: The Case of the New York City Market. Northeast. J. Agr. and Resour. Econ., in press.

- Media Advertising Effects on Milk Demand: The Case of the Buffalo, New York, Market with an Empirical Comparison of Alternative Functional Forms of the Sales Response Equation. Agr. Econ. Res. Pap. No. 83-13, Cornell University, Feb. 1983.

- Seasonality in Long-Run Advertising Elasticities for Fluid Milk: An Application of Smoothness Priors. Agr. Econ. Res. Pap. No. 81-9, Cornell University, July 1981 .

Kling, Herbert. "Minutes of the Thirteenth Meeting of the Fourth State Milk Promotion Board." Albany: New York State Department of Agriculture and Markets, 4 Nov. 1982.

Lambin, J. J. Advertising, Competition and Market Conduct in Oligopoly Over Time. Amsterdam: NorthHolland Publishing Co., 1976.

Market Administrator's Bulletin. New York-New Jersey Milk Marketing Area. Annual report, various issues, 1977-79.

Nerlove, M., and K. J. Arrow. "Optimal Advertising Policy Under Dynamic Conditions." Economica 29(1962):129-42.

Nerlove, M., and F. V. Waugh. "Advertising without Supply Control: Some Implications of a Study of the Advertising of Oranges." J. Farm Econ. 43(1961): 813-37.

Novakovic, Andrew M. "A Detailed Study of the Dairy Production Stabilization Act of 1983." Cornell University Agr. Econ. Staff Pap. No. 83-26, Dec. 1983.

Pesando, J. E. "Seasonal Variability in Distributed Lag Models." J. Amer. Statist. Assoc. 67(1972):311-12.

Rao, P., and R. L. Miller. Applied Econometrics. Belmont CA: Wadsworth Publishing Co., 1971.

Simon, J. L., and J. Arndt. "The Shape of the Advertising Response Function." J. Advert. Res., no. 4 (1980), pp. 11-28. 
Theil, Henri. Principles of Econometrics. New York: John Wiley \& Sons, 1971.

Thompson, S. R., and D. A. Eiler. "Determinants of Milk Advertising Effectiveness." Amer. J. Agr. Econ. 59(1977):330-35.

. "Producer Returns from Increased Milk Advertising." Amer. J. Agr. Econ. 57(1975):505-08.

Thompson, S. R., D. A. Eiler, O. D. Forker. "An Econometric Analysis of Sales Response to Generic Milk Advertising in New York State." Search: Agriculture, Cornell University Agr. Exp. Sta. No. 6, 1976.

Trivedi, P. K., and B. M. S. Lee. "Seasonal Variability in a Distributed Lag Model." Rev. Econ. Stud. 48(1981):497-505.

U.S. Department of Agriculture, Economic Research Service. Dairy Outlook and Situation. DS-387, Washington DC, Dec. 1981.

Wallace, T. Dudley. "Pretest Estimation in Regression: A Survey." Amer. J. Agr. Econ. 59(1977):431-43.

Wallis, K. F. "Testing for Fourth-Order Autocorrelation in Quarterly Regression Equations." Econometrica 40(1972):617-36.

Zielske, Hubert. "The Remembering and Forgetting of Advertising." J. Mktg 23(1959):239-43. 